\title{
Oral Health Impact Profile (OHIP-14) and its association with dental treatment needs of adolescents in a rural Nigerian community
}

\author{
Lawal Folake Barakat, BDS, MDS,FMCDS, FWACS'; Ifesanya Joy Ucheonye BDS, MPH, FMCDS² \\ ${ }^{1}$ Department of Periodontology and Community Dentistry, University of Ibadan, Ibadan and University College Hospital, Ibadan \\ ${ }^{2}$ Department of Child Oral Health, University of Ibadan, Ibadan and University College Hospital, Ibadan
}

Received for publication: November 11, 2016 Accepted: June 12, 2017

Correspondence: Dr Joy U Ifesanya, Department of Child Oral Health,

Faculty of Dentistry,

College of Medicine, University of Ibadan, PMB 5017, Ibadan, Nigeria 200212

E-mail- joyifesanya@yahoo.co.uk Telephone- +2348055623129

\section{Abstract}

Aim: To validate and determine the applicability of OHIP-14 in assessing the impact of unmet dental treatment needs on the quality of life of adolescents in a rural community. Methods: The OHIP-14 questionnaire and the Aesthetic component (AC) of Index of Orthodontic Treatment Need (IOTN) were data collection instruments in a cross sectional survey among students in a rural community. The reliability and validity of the OHIP-14 as well as the association between it and dental treatment needs including malocclusion was assessed. Data obtained was analyzed using Mann Whitney $\mathrm{U}$ Test. Results: The mean age of participants was $14.9( \pm 1.6)$ years. The OHIP-14 had acceptable Cronbach alpha value of 0.8 . It could discriminate between respondents with or without dental treatment needs due to caries and dental trauma $(p<0.001)$. The OHIP-14 did not differentiate between respondents with or without orthodontic treatment need $(p=0.808)$. However, significant association existed between being irritable with people and unmet orthodontic treatment needs $(p=0.032)$. Conclusion: The OHIP-14 is a valid and reliable quality of life assessment tool in young adolescents in this rural community. However, only the social disability domain component discriminated significantly between those with or without orthodontic treatment needs.

Keywords: Quality of life. OHIP-14. Malocclusion. Dental treatment needs. Adolescents.

\section{Introduction}

The concept of Oral Health Related Quality of Life(OHRQoL), involves the use of multidimensional constructs that assess the absence or presence of negative impacts of oral health conditions and diseases on the day to day wellbeing of an individual ${ }^{1,2}$. OHRQoL was borne out of the paradigm shift from the assessment of oral health merely on the basis of clinical presence or absence of disease ${ }^{3}$. OHRQoL does not assess health solely from the standpoint of the managing physician who assesses clinical signs and symptoms as the major yardsticks, but primarily incorporates the subjective (selfperceived) opinion of the patient affected by the oral condition being assessed. The subjective assessment of the impact of oral conditions on quality of life has been found useful in the planning and evaluation of oral health programmes, dental care services and instituted treatments ${ }^{4,5}$. These tools are especially valuable in rural communities of developing countries where appropriate allocation, monitoring and evaluation of sparse resources are very important. The additional merit of providing insights into individuals' perception of the effect of oral diseases and conditions on their daily performances is of 
great value ${ }^{6}$. This is especially true as it has been established that the absence of perceived needs is a major factor for not utilizing dental services ${ }^{3}$.

Rural communities in many parts of Africa are faced with inaccessibility to and poor utilization of dental care services and high unmet dental needs both in children and adults ${ }^{7-10}$. Children in these communities are noted to have poor oral hygiene and high prevalence of untreated dental caries ${ }^{8,11,12}$. Unmet dental needs due to dental caries have negative impact on the daily activities of children with functional domain mostly affected ${ }^{13}$. Oral conditions such as malocclusion have also been associated with impacts on the quality of life of affected individuals ${ }^{14}$ and affecting the psychological and social domains most ${ }^{15,16}$. This is especially important among adolescents who are undergoing physical, psychological, emotional and social life changes, and are under various forms of pressure to be accepted by their peers, while maintaining their 'status' in the home front ${ }^{17}$. The effect of treating the aforementioned oral conditions have shown significant reduction or elimination of the self-perceived negative impact on the quality of life of those affected ${ }^{13,18}$. This is one of the major advantages of using quality of life measures. Numerous OHRQoL measures exist which have not been utilized in Nigerian rural communities. One of these is the Oral Health Impact Profile (OHIP-14), which is easy to use, and has been validated and found acceptable in many regions ${ }^{19-21}$ as well as among adult Nigerians in an urban region ${ }^{22}$. The evaluation of this instrument for comprehensive use both in the adult and adolescent Nigerian population will require its validation, as well as the determination of its applicability in the young adolescent in rural communities with diverse cultural norms and values. The OHIP14 has however been evaluated and documented among Brazilian adolescents where it was found to be valid and acceptable for assessing OHRQoL ${ }^{23}$. Its discriminative properties to determine adolescents' response to orthodontic treatment has also been previously assessed ${ }^{23}$.

This study aimed to validate and determine the applicability of OHIP-14 in assessing the impact of unmet dental treatment needs on the quality of life of adolescents in a rural community in Nigeria.

\section{Materials and methods}

This is a cross sectional study conducted among secondary school students in randomly selected schools in a rural community in Southwestern Nigeria over a period of six weeks. A minimum sample size of 384 was calculated at $5 \% \alpha$-level $\left(Z_{\alpha}=1.96\right)$ and difference margin of $5 \%$ using maximum prevalence of $50 \%$ with the formula for cross sectional studies ${ }^{24}$.

Following ethical approval from the State Ethics Review Committee, approval and permission to conduct the study in selected schools was obtained from the Local Inspector of Education and the Local Government Schools' Board. Schools from which students were recruited for the study were selected by simple random sampling technique through balloting from the list of schools within the community that was provided by the Local Government Central Schools' Board. The head teachers of the selected schools and class teachers of junior secondary school one to three (Grade 7-9) were approached, the purpose of the study was explained and permission to conduct the study was obtained. All Grade 7-9 students who were eligible for the study were approached and only those who assented and were available at the time of the study were recruited. Illness and negative parental consent led to exclusion from the study.

Instrument of data collection was OHIP-14 questionnaire, which comprises of 14 questions with two questions each under seven domains. The domains include; functional limitation, physical pain, psychological discomfort, physical disability, psychological disability, social disability and handicap ${ }^{19}$. Responses to the questions are based on a Likert scale which ranged from 0- "never" to 4- "very often". Variables also included in the questionnaire were: demographic variables and satisfaction ratings of teeth appearance and self- rating of tooth condition. The satisfaction ratings of tooth appearance assessed how satisfied the participants were with the appearance of their teeth with a response of "satisfied or dissatisfied". The self- rating of tooth condition assessed oral condition as being "good or poor". The satisfaction ratings and self-ratings of oral health were variables used to assess the construct validity of OHIP-14 in the respondents. The questionnaire was translated to Yoruba language by language professionals and back-translated by two independent research assistants with minimal modification required. The backtranslated questionnaire showed that the true meaning of the domains of the OHIP-14 was preserved in the Yoruba version. Due to the significant language barrier in the rural community of interest, the Yoruba language translation of the questionnaire was pretested among 30 students from other schools different from those selected for the study to ascertain the feasibility of self-administration as well as its comprehensiveness. The Yoruba translation of the OHIP-14 was subsequently administered to the students assessed in this study. In addition to administration of the OHIP-14 questionnaire, oral examination was conducted by a trained examiner to determine the treatment needs of the participants. The orthodontic treatment need was assessed using the Aesthetic Component (AC) of the Index of Orthodontic Treatment Need (IOTN). The IOTN-AC scores were coded as:

\begin{tabular}{|c|c|}
\hline $\begin{array}{l}\text { No orthodontic treatment need } \\
\text { Borderline need } \\
\text { Definite treatment need }\end{array}$ & $\begin{array}{l}\text { AC grade } 1-4 \\
\text { AC grade } 5-7 \\
\text { AC grade } 8-10\end{array}$ \\
\hline
\end{tabular}

Need for orthodontic treatment comprised of AC scores (5-10); borderline grade (5-7) and definite treatment need grade (8-10) were coded together in this category.

Need for other dental treatments due to presence of dental caries and trauma were documented as "present or absent" and considered as "other unmet dental treatment needs".

The reliability of OHIP-14 for internal consistency was determined by Cronbach's alpha and its stability assessed by the intra-class correlation coefficient. The Cohen kappa statistics for the test re-test reliability was conducted among 20 students who had duplicate interviews at an interval of one week.

The total OHIP score for the respondents was calculated by adding the responses score for each item together to give a minimum score of 0 and maximum score of 56. An impact on the quality of life was considered at a response level of hardly 
ever. The face validity of the OHIP-14 was determined by interviewing dentists, while the construct validity was assessed by the association between self-ratings of oral health and satisfaction of the participant with their OHIP-14 scores. The discriminant validity was determined by comparing OHIP-14 scores in those with or without treatment needs for malocclusion with OHIP-14 scores of subjects with or without treatment need as a result of dental caries and trauma.

Data collected were processed and analyzed with SPSS version 21. Test of association was done using Mann Whitney $U$ statistics since the data was skewed. Level of significance was set at $<5 \%$. Kappa statistics was used to determine test-retest reliability of OHIP-14 and cut off level for significance set at $\mathrm{p}<5 \%$.

\section{Results}

Overall, 395 students participated in the study. The mean age of the study participants was $14.9( \pm 1.6)$ years. The male gender accounted for $222(53.6 \%)$ of the participants, the rest were females.

\section{Reliability of OHIP-14}

The Cronbach alpha value for internal consistency of the OHIP-14 was 0.84 . The inter item coefficient ranged from 0.1 to 0.6 with no negative values and intra class correlation coefficient was 0.83 . Deletion of any of the items of the OHIP-14 resulted in lower Cronbach alpha values compared with the standardized alpha value (Table1).

Table1 - Internal consistency of OHIP-14

\begin{tabular}{lll}
\hline OHIP Item & $\begin{array}{l}\text { Scale mean if item is } \\
\text { deleted }\end{array}$ & $\begin{array}{l}\text { Cronbach alpha if } \\
\text { item is deleted }\end{array}$ \\
\hline Trouble pronouncing words & 3.06 & 0.825 \\
Worsened sense of taste & 3.10 & 0.826 \\
Painful aching & 2.90 & 0.836 \\
Uncomfortable eating & 3.03 & 0.824 \\
Self-consciousness & 3.14 & 0.827 \\
Felt nervous & 3.14 & 0.829 \\
Diet been unsatisfactory & 3.01 & 0.822 \\
Meals interrupted & 3.04 & 0.826 \\
Difficulty to relax & 3.16 & 0.825 \\
Embarrassment & 3.10 & 0.825 \\
Irritable with other people & 3.21 & 0.833 \\
Difficulty doing school work & 3.25 & 0.831 \\
Life less satisfying & 3.26 & 0.829 \\
Unable to perform usual function & 3.23 & 0.835 \\
Scale mean & 3.35 & \\
Cronbach alpha & & 0.84 \\
\hline
\end{tabular}

\section{Validity of OHIP-14}

The face and content validity was assessed by a team of dentists and the participants, and it was made known that the instrument assessed how oral health affected the daily activities of individuals, all questions were simple to understand and straightforward.
The construct validity as assessed by comparison of OHIP14 scores with a proxy since there is no overall gold standard to evaluate the criterion validity. The OHIP-14 scores when compared with pain, self-perceived treatment need, global self-rating of oral health, satisfaction rating of oral health condition and tooth appearance were all statistically significant (Table 2). The mean and median OHIP-14 score was higher in participants who were dissatisfied with their oral health condition and tooth appearance, who rated their oral health poorly, perceived a need for dental treatment or experienced pain compared with those who did not report any of the aforementioned variables $(p<0.05)$

Table 2 - The discriminant and construct validity of the OHIP-14 questionnaire

\begin{tabular}{|c|c|c|c|}
\hline Variable & \multicolumn{2}{|l|}{ OHIP-14 } & $P$ value \\
\hline \multicolumn{4}{|c|}{ Self-rating of oral health } \\
\hline Good & $2.5( \pm 4.6)$ & 0.0 & $<0.001^{*}$ \\
\hline Poor & $6.8( \pm 8.0)$ & 5.0 & \\
\hline \multicolumn{4}{|c|}{ Satisfaction ratings of oral condition } \\
\hline Satisfied & $2.7( \pm 4.7)$ & 0.0 & $<0.001^{*}$ \\
\hline Dissatisfied & $6.4( \pm 8.4)$ & 3.0 & \\
\hline \multicolumn{4}{|c|}{ Satisfaction ratings of tooth appearance } \\
\hline Satisfied & $2.7( \pm 5.0)$ & 0.0 & $<0.001^{*}$ \\
\hline Dissatisfied & $7.6( \pm 7.5)$ & 6.0 & \\
\hline \multicolumn{4}{|c|}{ Perceived need for treatment } \\
\hline No & $1.9( \pm 4.1)$ & 0.0 & $<0.001^{*}$ \\
\hline Yes & $5.4( \pm 6.8)$ & 3.0 & \\
\hline \multicolumn{4}{|l|}{ Pain } \\
\hline No & $1.7( \pm 3.4)$ & 0.0 & $<0.001^{*}$ \\
\hline Yes & $8.2( \pm 7.8)$ & 6.0 & \\
\hline \multicolumn{4}{|c|}{ Normative Orthodontic treatment need } \\
\hline No & $3.1( \pm 5.3)$ & 1.0 & 0.808 \\
\hline Yes & $3.7( \pm 6.2)$ & 1.0 & \\
\hline \multicolumn{4}{|c|}{ Other Normative dental treatment needs } \\
\hline No & $3.0( \pm 5.2)$ & 0.0 & $<0.001^{*}$ \\
\hline Yes & $6.5( \pm 7.4)$ & 6.0 & \\
\hline \multicolumn{4}{|c|}{ Categories of orthodontic treatment needs } \\
\hline No need & $3.1( \pm 5.3)$ & 1.0 & 0.920 \\
\hline Borderline & $3.3( \pm 5.2)$ & 1.0 & \\
\hline Definite need & $5.8( \pm 9.6)$ & 0.0 & \\
\hline
\end{tabular}

\section{OHIP-14 and dental treatment needs}

There were $157(39.7 \%)$ respondents with "orthodontic treatment needs" of which $28(7.1 \%)$ had definite orthodontic treatment needs. Thirty-nine respondents $(9.9 \%)$ had "other dental treatment needs" due to dental trauma and caries. The OHIP-scores ranged from 0-37 with a mean score of 3.4 \pm 5.7. The mean OHIP-14 score for those with "other dental treatment needs" was $6.5 \pm 7.4$, and was generally higher than mean score for those with "orthodontic treatment needs" (Table 2). Two hundred and two $(51.5 \%)$ respondents perceived an impact on their quality of life due to oral diseases and conditions, while 155 (39.0\%) had some form of need for orthodontic treatment as assessed by the aesthetic component of the IOTN. Mean OHIP scores increased with increased need for orthodontic treatment; however, this was not statistically significant. (Table 2)

A significantly higher proportion of respondents with "other dental needs" reported impacts on their quality of life from; 
worsened sense of taste, painful aching, discomfort with eating, self-consciousness, nervousness, unsatisfactory diet, meals being interrupted, embarrassment, irritability, difficulty doing school work and inability to function (Table 3 ). However, the only significant impact effect as a result of unmet orthodontic treatment need was being irritable with people (Table 3).

Table 3 - relationship between the OHIP-14 questionnaire items and the various unmet dental treatment needs

\begin{tabular}{|c|c|c|c|c|c|c|}
\hline \multirow[t]{2}{*}{ OHIP Item } & \multicolumn{2}{|c|}{ Orthodontic treatment need } & \multirow[t]{2}{*}{ P-value } & \multicolumn{2}{|c|}{ Other dental treatment needs } & \multirow[t]{2}{*}{$P$ value } \\
\hline & Yes $\mathrm{N}(\%)$ & No $\mathrm{N}(\%)$ & & Yes $N(\%)$ & No $\mathrm{N}(\%)$ & \\
\hline \multicolumn{7}{|l|}{ Functional limitation } \\
\hline \multicolumn{7}{|l|}{ Trouble pronouncing words } \\
\hline Impact & $21(13.4)$ & $20(8.4)$ & 0.742 & $5(12.8)$ & $36(10.1)$ & 0.330 \\
\hline No impact & $136(86.6)$ & $203(81.6)$ & & $34(87.2)$ & $320(89.9)$ & \\
\hline \multicolumn{7}{|l|}{ Worsened sense of taste } \\
\hline Impact & $25(42.4)$ & $34(57.6)$ & 0.655 & $10(25.6)$ & $20(5.6)$ & $0.001^{*}$ \\
\hline No impact & $132(39.3)$ & $204(60.7)$ & & $29(74.4)$ & $336(92.3)$ & \\
\hline \multicolumn{7}{|l|}{ Physical pain } \\
\hline \multicolumn{7}{|l|}{ Painful aching } \\
\hline Impact & $27(17.2)$ & $41(17.2)$ & 0.468 & $9(23.1)$ & $59(16.6)$ & $<0.001^{*}$ \\
\hline No impact & $130(82.8)$ & $197(82.8)$ & & $30(76.9)$ & $297(83.4)$ & \\
\hline \multicolumn{7}{|l|}{ Uncomfortable eating } \\
\hline Impact & $15(9.6)$ & $31(13.0)$ & 0.580 & $9(23.1)$ & $37(10.4)$ & $0.002^{*}$ \\
\hline No impact & $142(90.4)$ & $207(87.0)$ & & $30(76.9)$ & $319(89.6)$ & \\
\hline \multicolumn{7}{|l|}{ Psychological discomfort } \\
\hline \multicolumn{7}{|l|}{ Self-consciousness } \\
\hline Impact & $12(7.6)$ & $12(5.0)$ & 0.122 & $6(15.4)$ & $18(5.1)$ & $0.001^{*}$ \\
\hline No impact & $145(92.4)$ & $226(95.0)$ & & $33(84.6)$ & $338(94.9)$ & \\
\hline \multicolumn{7}{|l|}{ Felt nervous } \\
\hline Impact & $15(9.6 \%)$ & $11(4.6)$ & 0.079 & $6(15.4)$ & $20(5.6)$ & $0.013^{*}$ \\
\hline No impact & $142(90.4)$ & $227(95.4)$ & & $33(84.6)$ & $336(94.4)$ & \\
\hline \multicolumn{7}{|l|}{ Physical disability } \\
\hline \multicolumn{7}{|l|}{ Diet been unsatisfactory } \\
\hline Impact & $16(10.2)$ & $26(10.9)$ & 0.641 & $11(28.2)$ & $31(8.7)$ & $<0.001$ \\
\hline No impact & $141(89.8)$ & $212(89.1)$ & & $28(71.8)$ & $325(91.3)$ & \\
\hline \multicolumn{7}{|l|}{ Interrupted meals } \\
\hline Impact & $22(14.0)$ & $17(7.1)$ & 0.073 & $4(10.3)$ & $35(9.8)$ & $0.024^{*}$ \\
\hline No impact & $135(86.0)$ & $221(92.9)$ & & $35(89.7)$ & $321(90.2)$ & \\
\hline \multicolumn{7}{|l|}{ Psychological disability } \\
\hline \multicolumn{7}{|l|}{ Difficulty to relax } \\
\hline Impact & $7(4.5)$ & $17(7.1)$ & 0.606 & $3(7.7)$ & $21(5.9)$ & 0.516 \\
\hline No impact & $150(95.5)$ & $221(92.9)$ & & $36(92.3)$ & $335(94.1)$ & \\
\hline \multicolumn{7}{|l|}{ Embarrassment } \\
\hline Impact & $14(8.9)$ & $15(6.3)$ & 0.676 & $7(17.9)$ & $22(6.2)$ & $0.023^{*}$ \\
\hline No impact & $143(91.1)$ & $223(93.7)$ & & $32(82.1)$ & $334(93.8)$ & \\
\hline Social disability & & & & & & \\
\hline Irritable with other people & & & $0.032^{*}$ & $6(15.4)$ & $8(2.2)$ & $<0.001^{*}$ \\
\hline Impact & $9(5.7)$ & $5(2.1)$ & & $33(84.5)$ & $348(97.8)$ & \\
\hline No impact & $148(94.3)$ & $233(97.9)$ & & & & \\
\hline Difficulty doing school work & & & & & & \\
\hline Impact & $4(2.5)$ & $10(4.2)$ & 0.581 & $3(7.7)$ & $11(3.1)$ & $0.020^{*}$ \\
\hline No impact & $153(97.5)$ & $228(95.8)$ & & $36(92.3)$ & $345(96.9)$ & \\
\hline Handicap & & & & & & \\
\hline Life less satisfying & & & & & & \\
\hline Impact & $3(1.9)$ & $10(4.2)$ & 0.051 & $4(10.3)$ & $9(2.5)$ & 0.064 \\
\hline No impact & $154(98.1)$ & $228(95.8)$ & & $35(89.7)$ & $347(97.5)$ & \\
\hline Unable to function & & & & & & \\
\hline Impact & $5(3.5)$ & $9(3.8)$ & 0.606 & $1(2.6)$ & $13(3.7)$ & $<0.001^{*}$ \\
\hline No impact & $152(96.5)$ & $229(96.2)$ & & $38(97.4)$ & $343(96.3)$ & \\
\hline
\end{tabular}

*Statistically significant with Mann Whitney U test

\section{Discussion}

This study has observed that the OHIP-14 is a valid tool for assessing oral health related quality of life among this group of rural dwelling adolescents as it demonstrated a value for internal consistency higher than the recommended 0.7 value ${ }^{25}$. The construct validity is also of great value among these children as the OHIP-14 was able to detect significant difference in quality of life experiences among participants who required oral health intervention when compared to those that did not. In this study, the mean OHIP-14 scores were highest among people who felt pain and those who were dissatisfied with the appearance of their teeth followed by those who rated their oral health as being poor or were dissatisfied with their oral conditions. This is similar to finding in previous studies where higher impacts were observed when 
self-perceived oral health was poor ${ }^{26,27}$. More participants in this rural community based study reported an impact of their general dental wellbeing on their quality of life than in a previous study among urban Nigerian children ${ }^{28}$. This is probably a reflection of the lower oral health utilization among rural dwellers in this environment with attendant higher disease burden ${ }^{10,29}$.

In the present study, when 'other oral health needs' were compared to orthodontic treatment need however, the OHIP-14 had better discriminant value for assessing oral health related quality of life associated to caries and trauma than quality of life associated with malocclusion. Previous studies have reported weak relationship between orthodontic indices and OHRQoL tools $\mathrm{s}^{30,31}$. This is partly because malocclusion itself is not necessarily a disease, but a series of deviations from the dental norm $^{1}$. As a result, perception of need for treating malocclusion may be overlooked as long as functionality and aesthetics are not affected ${ }^{32,33}$. On the other hand, orthodontists view the occlusion more intensively than lay individuals do; and unless the malocclusion is critically severe, the patients' views may never match that of the orthodontist. The insignificant relation between the OHIP-14 and OHRQoL due to malocclusion in this study may also be attributed to the fact that rural children are less knowledgeable about malocclusion than urban children. Anosike et al., had reported more social impact on OHRQoL due to malocclusion among urban dwelling children than observed in this rural based study ${ }^{28}$. In addition, studies have reported that social class is a major factor among people seeking treatment of malocclusion $^{34,35}$. Since most of these rural children are not from the high socioeconomic class, the low social status may also be a contributory factor. As a result of the aforementioned, these rural children cannot claim to be affected by a concept or condition they are not fully aware of. This argument poses a limitation on this study and needs to be verified by a study comparing OHRQoL experiences and malocclusion between urban and rural children. Another limitation is that only the aesthetic component of the IOTN was assessed in this study which does not necessarily impact on the objective functional capabilities of the adolescents assessed.

The social disability domain of the OHIP-14 detected that children who felt a need for orthodontic treatment were more irritable than those who did not and this agrees with a previous study of urban children where the psychosocial domain was most noted to impact on quality of life of the children as far as self-perceived orthodontic need was concerned ${ }^{28}$. This further emphasizes the social impact of malocclusion on OHRQoL of individuals.

In conclusion, the OHIP-14 is a valid tool for assessing OHRQoL of dental treatment needs as a result of caries and trauma among rural Nigerian children. However, it appears to be valid only in detecting the social impact of normative orthodontic treatment needs. Validating and assessing the applicability of other OHRQoL measures in this environment is recommended.

\section{References}

1. Salim Z, Majid A. Effects of malocclusion on Oral Health Related Quality of Life (OHRQoL): A critical review. Eur J Oral Sci. 2014 Jun;122(3):223-9. doi: 10.1111/eos.12130.
2. U.S Department of Health Services. Oral Health in America: A report of the Surgeon General. Rockville, MD: U.S Department of Health and Human Services, National Institute of Dental and Craniofacial Research, National Institutes of Health; 2000.

3. Al-Shamrany M. Oral Health-Related Quality of Life : a broader perspective. East Mediterr Health J. 2006 Nov;12(6):894-901.

4. Allen PF, McMillan AS, Locker D. An assessment of sensitivity to change of the Oral Health Impact Profile in a clinical trial. Community Dent Oral Epidemiol. 2001 Jun;29(3):175-82.

5. Locker D, Jokovic A, Clarke M. Assessing the responsiveness of measures of oral health-related quality of life. Community Dent Oral Epidemiol. 2004 Feb;32(1):10-8.

6. Sischo L, Broder HL. Oral health-related quality of life: what, why, how, and future implications. J Dent Res. 2011 Nov;90(11):1264-70. doi: 10.1177/0022034511399918

7. Varenne B, Msellati P, Zoungrana C, Fournet F, Salem G. Reasons for attending dental-care services in Ouagadougou, Burkina Faso. Bull World Health Organ. 2005 Sep;83(9):650-5.

8. Okolo SN, Chukwu GA, Egbuonu I, Ezeogu FA, Onwuanaku C, Adeleke $\mathrm{OA}$, et al. Oral hygiene and nutritional status of children aged 1-7 years in a rural community. Ghana Med J. 2006 Mar;40(1):22-5.

9. Ajayi DM, Arigbede AO. Barriers to oral health care utilization in Ibadan, South West Nigeria. Afr Health Sci. 2012 Dec;12(4):507-13.

10. Azodo CC, Amenaghawon OP. Oral hygiene status and practices among rural dwellers. Eur J Gen Dent. 2013;2(1):42-5.

11. Sofola OO, Shaba OP, Jeboda SO. Oral hygiene and periodontal treatment needs of urban school children compared with that of rural school children in Lagos State. Nigeria. Odontostomatol Trop. 2003 Mar;26(101):25-9.

12. Okeigbemen SA. The prevalence of dental caries among 12 to 15-year-old school children in Nigeria: report of a local survey and campaign. Oral Health Prev Dent. 2004;2(1):27-31.

13. Alsumait A, ElSalhy M, Raine K, Cor K, Gokiert R, Al-Mutawa S, et al. Impact of dental health on children's oral health-related quality of life: a cross-sectional study. Health Qual Life Outcomes. 2015 Jul 7;13:98. doi: 10.1186/s12955-015-0283-8.

14. Bernabé E, Sheiham A, Tsakos G, Messias De Oliveira C. The impact of orthodontic treatment on the quality of life in adolescents: A case-control study. Eur J Orthod. 2008 Oct;30(5):515-20. doi: 10.1093/ejo/cjn026

15. Bernabé E, Sheiham A, De Oliveira CM. Condition-specific impacts on quality of life attributed to malocclusion by adolescents with normal occlusion and class I, II and III malocclusion. Angle Orthod. 2008 Nov;78(6):977-82. doi: 10.2319/091707-444.1.

16. Masood Y, Masood M, Zainul NNB, Araby NBAA, Hussain SF, Newton T. Impact of malocclusion on oral health related quality of life in young people. Health Qual Life Outcomes. 2013 Feb 26;11:25. doi: 10.1186/1477-7525-11-25.

17. Curtis AC. Defining Adolescence. J Adolesc Fam Health. 2015;7(2):139.

18. Chukwumah NM, Folayan MO, Oziegbe EO, Umweni AA. Impact of dental caries and its treatment on the quality of life of 12- to 15-year-old adolescents in Benin, Nigeria. Int J Paediatr Dent. 2016 Jan;26(1):66-76. doi: 10.1111/ipd.12162.

19. Slade GD. The Oral Health Impact Profile. In: Slade GD, ed. Measuring Oral Health and Quality of Life. Chapel Hill: University of North Carolina, Dental Ecology; 1997. p.93-104.

20. Bae K-H, Kim H-D, Jung S-H, Park D-Y, Kim J-B, Paik D-I, et al. Validation of the Korean version of the oral health impact profile among the Korean elderly. Community Dent Oral Epidemiol. 2007 Feb;35(1):73-9.

21. Kotzer RD, Lawrence HP, Clovis JB, Matthews DC. Oral health-related quality of life in an aging Canadian population. Health Qual Life Outcomes. 2012 May 15;10:50. doi: 10.1186/1477-7525-10-50. 
22. Lawal FB, Taiwo JO, Arowojolu MO. How valid are the psychometric properties of the oral health impact profile-14 measure in adult dental patients in Ibadan, Nigeria? Ethiop J Heal Sci. 2014 Jul;24(3):235-42.

23. de Oliveira CM, Sheiham A, Tsakos G, O'Brien KD. Oral health-related quality of life and the IOTN index as predictors of children's perceived needs and acceptance for orthodontic treatment. Br Dent J. $2008 \mathrm{Apr}$ 12;204(7):1-5; discussion 384-5. doi: 10.1038/bdj.2008.239.

24. Leslie K. Survey sampling. New York: John Wiley and Sons, Inc; 1965. p.78-94.

25. Streiner DL. Starting at the beginning: an introduction to coefficient alpha and internal consistency. J Pers Assess. 2003 Feb;80(1):99103.

26. Montero-Martín J, Bravo-Pérez M, Albaladejo-Martinez A, Hernandez-Martin LA, Rosel-Gallardo EM. Validation the oral health impact profile (OHIP-14sp) for adults in Spain. Med Oral Patol Oral Cir Bucal. 2009 Jan 1;14(1):E44-50. Available from: http://www.medicinaoral. com/pubmed/medoralv14_i1_p44.pdf.

27. Hongxing L, List T, Nilsson I-M, Johansson A, Astrøm AN. Validity and reliability of OIDP and OHIP-14: a survey of Chinese high school students. BMC Oral Health. 2014 Dec 19;14:158. doi: 10.1186/14726831-14-158. Available from: http://bmcoralhealth.biomedcentral.com/ articles/10.1186/1472-6831-14-158.
28. Anosike AN, Sanu OO, da Costa OO. Malocclusion and its Impact on Quality of Life of School Children in Nigeria. West Afr J Med. 2010 Nov-Dec;29(6):417-24.

29. Sofola OO. Implications of Low Oral Health Awareness in Nigeria. Niger Med J. 2010;51(3):131-3.

30. de Oliveira CM, Sheiham A. Orthodontic treatment and its impact on oral health-related quality of life in Brazilian adolescents. J Orthod. 2004 Mar;31(1):20-7.

31. Ashari A, Mohamed AM. Relationship of the Dental Aesthetic Index to the oral health-related quality of life. Angle Orthod. 2016 Mar;86(2):337-42. doi: 10.2319/121014-896.1.

32. Roberts-Harry D, Sandy J. Orthodontics. Part 11: Orthodontic tooth movement. Br Dent J. 2004 Apr;196(7):391-4.

33. Agarwal SS, Jayan B, Chopra SS. An Overview of Malocclusion in India. J Dent Health Oral Disord Ther. 2015;3(3):1-4.

34. Adeyemi AT, Aderiokun GA, Denloye OO. Socio-economic status and utilization of orthodontic services in a Nigerian hospital. Odontostomatol Trop. 2008 Jun;31(122):27-33.

35. Badran SA, Al-Khateeb S. Factors influencing the uptake of orthodontic treatment. J Public Health Dent. 2013 Fall;73(4):339-44. doi: 10.1111/jphd.12034. 